\title{
Intertrial interval and unconditioned stimulus durations in autoshaping
}

\author{
PETER D. BALSAM \\ Barnard College, New York, New York 10027 \\ and \\ DAVID PAYNE \\ Columbia University, New York, New York 10027
}

\begin{abstract}
Four groups of pigeons were exposed to an autoshaping procedure in which a 20-sec key illumination preceded the presentation of response-independent grain. The groups differed according to the duration of feeder access and the intertrial intervals. If feeder durations are not included in the time between trials, two of the groups had identical intertrial intervals. If feeder durations are included, each of the other two groups was identical to one of the first two in terms of the intertrial interval. The speed of acquisition and maintained measures of responding were directly related to the duration of the interval from food offset to signal onset. Groups exposed to equivalent intertrial intervals and different feeder durations did not differ from one another on these measures. The results were interpreted as evidence that feeder durations were not included in the functional intertrial interval and that feeder duration, per se, did not affect autoshaped responding.
\end{abstract}

In the typical autoshaping experiment with pigeons, a Pavlovian delay procedure is employed in which the illumination of a key light, conditioned stimulus (CS), precedes the presentation of grain, the unconditioned stimulus (US). As in other classical conditioning preparations, the topography of the autoshaped conditioned response (CR) is influenced by the qualitative nature of the US (Jenkins \& Moore, 1973; Wasserman, 1973; Woodruff \& Williams, 1976). Unlike other classically conditioned responses, however, autoshaped keypecking seems uninfluenced by quantitative properties of the US. In appetitive salivary conditioning experiments, maintained levels of responding have been shown to be directly related to the quantity of food presented as the US (Gantt, 1938; Wagner, Siegal, Thomas, \& Ellison, 1964). In autoshaping experiments in which a single stimulus is correlated with a given US duration within each experimental session, the manipulation of feeder duration has not produced strong or reliable effects on keypecking (Balsam, Brownstein, \& Shull, 1978; Perkins, Beavers, Hancock, Hemmendinger, Hemmendinger, \& Ricci, 1975). Feeder durations in these studies ranged from 1 to $9 \mathrm{sec}$. Actual food access time, however, depended on the latency with which subjects began eating. The failure to detect

This research was supported by a grant from the Barnard College Research Committee. The authors wish to thank Rhona Gardner, Vivian Levmore, and Ida Markewich for their assistance in conducting the experiment. Reprints may be obtained from Peter Balsam, Department of Psychology. Barnard College, Columbia University, New York, New York 10027. an effect of feeder duration, therefore, may have been due to either the limited range of feeder values studied or to the discrepancy between programmed and actual food-access times. One purpose of the current study was to address these problems by comparing the effects of a very long feeder duration with one of a briefer duration and by achieving better experimental control over food-access times.

Another purpose of the experiment stems from the possibility that, in addition to whatever motivational effects the manipulation of feeder duration may have, the use of a very long feeder duration might influence behavior by altering temporal relationships. The speed of acquisition and maintained level of responding have been shown to be directly related to the duration of the intertrial interval (ITI) (Gibbon, Baldock, Locurto, Gold, \& Terrace, 1977; Terrace, Gibbon, Farrell, \& Baldock, 1975). In the usual autoshaping experiment, whether or not feeder durations are included in the ITI is of little consequence, because feeder times typically represent a small proportion of the time between trials. A very long feeder duration, however, might facilitate behavior by lengthening the ITI, thus confounding temporal effects with motivational ones. In order to assess this possibility, groups were included that permitted the assessment of whether or not feeder times were included in the functional ITI.

\section{METHOD}

\footnotetext{
Subjects

Twenty-two experimentally naive White Carneaux pigeons served as subjects. All birds were maintained at approximately $80 \%$
} 
of their free-feeding weights throughout the experiment. Three subjects were dropped from the study. Two were dropped because their eating was erratic and one because of an apparatus malfunction early in training.

\begin{abstract}
Apparatus
The experiments were conducted in two identical BRS/LVE 143-05 pigeon chambers measuring $33 \times 30 \times 30 \mathrm{~cm}$. Two response keys were located $25 \mathrm{~cm}$ above the floor and $8 \mathrm{~cm}$ from each side wall. The key nearest the rear wall could be transilluminated with green light by an IEE stimulus projector. The second key was available but inoperative. The feeder aperture was centered between the two keys and $12 \mathrm{~cm}$ above the floor. Two 24 PSB bulbs lit the magazine during grain presentation, and a photocell monitored head insertions into the aperture. Whenever the feeder was not operated, the chamber was illuminated by three No. 1824 bulbs centered in the ceiling. Each chamber was enclosed in a $3 / 4$-in. plywood chest whose speaker and ventilating fan provided continuous masking noise. Standard electromechanical programming equipment, housed in an adjacent room, was used to control the experiment and record data.
\end{abstract}

\section{Procedure}

The subjects were trained to eat in the chamber in one of two ways for reasons unrelated to the current experiment. Eleven subjects received from 100 to 200 feeder presentaions in which $4 \mathrm{sec}$ of access to grain, timed from head insertion in the aperture, were programmed on a variable-time 20 -sec schedule. Eight subjects were exposed to a second feeder training procedure in which each of six sessions began with the feeder already in the operated position. The feeder remained continuously operated until an observer recorded that the pigeon's head had been inside the feeder for a total of $300 \mathrm{sec}$. Two subjects in each of the four experimental groups had this history of feeder training. Both hopper training procedures resulted in reliable eating during the experimental phases.

Following hopper training, the subjects were assigned to one of four experimental groups. All subjects were given five autoshaping trials per day for 72 consecutive days. Each trial consisted of a 20 -sec illumination of the keylight, followed by grain presentation. All grain presentations were timed from the insertion of the subject's head into the feeder aperture. Keypecks were recorded, but had no scheduled consequence at any time.

Figure 1 shows that the experimental groups differed according to the durations of grain presentation and the time between trials. The four subjects in Group 1 were exposed to a 60 -sec US followed by a $24-\mathrm{sec}$ interval between reinforcer termination and the onset of the next trial. Group 2, with five subjects, and Group 3, with four subjects, were exposed to an 80 -sec interval from US offset to CS onset. Group 2 subjects were exposed to a 4-sec feeder duration, whereas Group 3 subjects were exposed to a 60 -sec grain presentation. The six subjects in Group 4 received 4-sec US presentations followed by a 136-sec interval from US of fset to CS onset.

It should be noted that if US duration is included in the time between trials, then Groups 1 and 2 and Groups 3 and 4 are exposed to equivalent temporal parameters. Alternatively, if US time is not included, Groups 2 and 3 are exposed to equivalent temporal values.

During the final five sessions (25 trials) of this phase of the experiment, an observer registered all pecking movements by depressing a microswitch in series with an electromechanical counter. This was done in order to assess whether or not automatically recorded pecks were representative of the conditioned response. The initial phase of the experiment ended after 360 trials.

In a second phase of the experiment, feeder durations were changed for three of the groups, while ITIs remained unaltered. Groups 1 and 3 were exposed to 4 -sec feeder durations, while Group 2 was switched to a $60-\mathrm{sec}$ feeder duration. This permitted an assessment of the effects of different feeder durations on

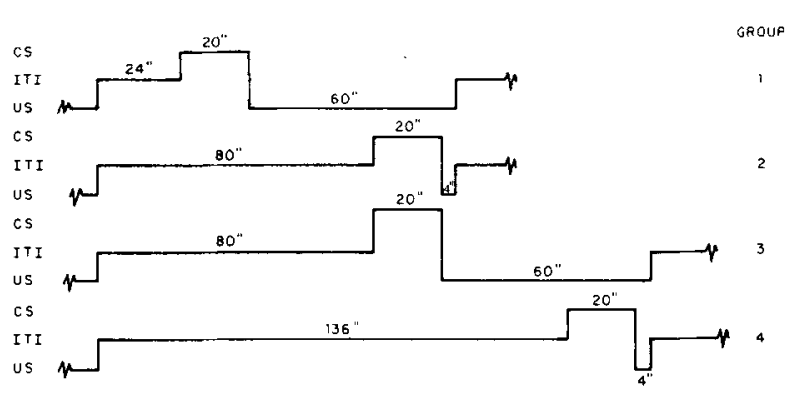

Figure 1. Schematic representation of the procedures used in the current experiment. The duration of the ITI, CS, and US is shown for each of the four experimental groups.

responding within individual subjects. Pigeons in Groups 2 and 3 were run for 5 trials per day for 40 days, whereas Group 1 pigeons received 20 trials per day for 10 days. As in Phase 1, the subjects were observed and pecking movements were recorded manually during the final five sessions. Group 4 pigeons did not participate in this phase of the experiment.

\section{RESULTS}

Three levels of acquisition and maintenance were obtained by the different experimental groups during Phase 1. The left portion of Figure 2 shows that three of the experimental groups were responding within the first block of four sessions (20 trials) and that the probability of responding showed significant increases over days $[F(17,255)=14.08, p<.01]$. The groups differed significantly in probability of responding $[\mathrm{F}(3,15)=5.68, \mathrm{p}<.01]$. In Group 4, five of the six subjects had high probabilities of responding while the remaining subjects showed a low probability of responding. In Groups 2 and 3, all but one subject in each group had moderate response probabilities. In Group 1, no subject acquired the keypeck response, although one subject pecked once during the first session. This pattern of individual

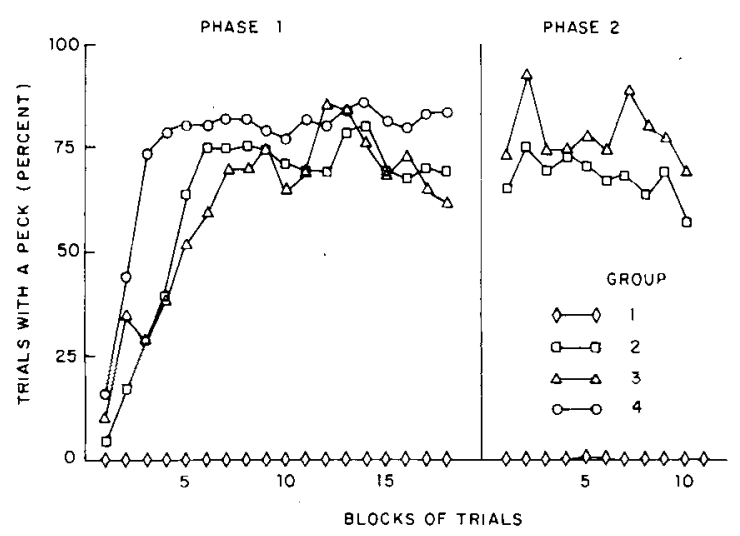

Figure 2. The mean percentage of trials with a response for each of the experimental groups. In Phase 1, all points are based on the mean block of four sessions ( 20 trials) for each subject. In Phase 2, all points represent blocks of 20 trials. Subjects in Groups 2 and 3 received 5 trials per session. Subjects in Group 4 received 20 trials per session. 
performance generated large within-group variability. A Newman-Keuls test of all possible differences between pairs of means consequently showed that Group 1 was significantly different from the other three groups $(p<.01)$, but none of the other three groups differed significantly from one another. A nonparametric analysis of the Phase 1 probabilities in Groups 2 and 3 confirmed the failure of the Newman-Keuls test to find a difference between these groups. These groups were consequently pooled and a median test revealed that Group 4 subjects had a significantly greater probability of responding than did subjects in Groups 2 and $3(p=.04)$.

A similar pattern of results was shown in the overall rate of responding during Phase 1 (left side of Figure 3). The mean overall rate of responding was highest for Group 4 subjects. Subjects in Groups 2 and 3 responded at moderate rates. For this measure, the within-groups variance was correlated with the group means. Therefore, the scores were transformed to logarithms, which reduced the heterogeneity of variance between groups. The statistical analysis revealed that the groups were significantly different from one another $[F(3,15)=5.01, p<.025]$ and that the rate of responding increased significantly over blocks $[\mathrm{F}(17,255)=10.20, \mathrm{p}<.01]$. The Groups by Blocks interaction was also significant $[\mathrm{F}(51,255)=1.74, \mathrm{p}<.01]$, primarily because of the failure of subjects in Group 1 to peck the key. The pattern of statistical comparisons between paired groups was identical to that previously described for the probability measure. During the last five sessions of Phase 1, the number of pecking movements during trials was observed and manually recorded. Subjects in Group 1 did not make any pecks. Subjects in Groups 2, 3, and 4 were observed to be making more

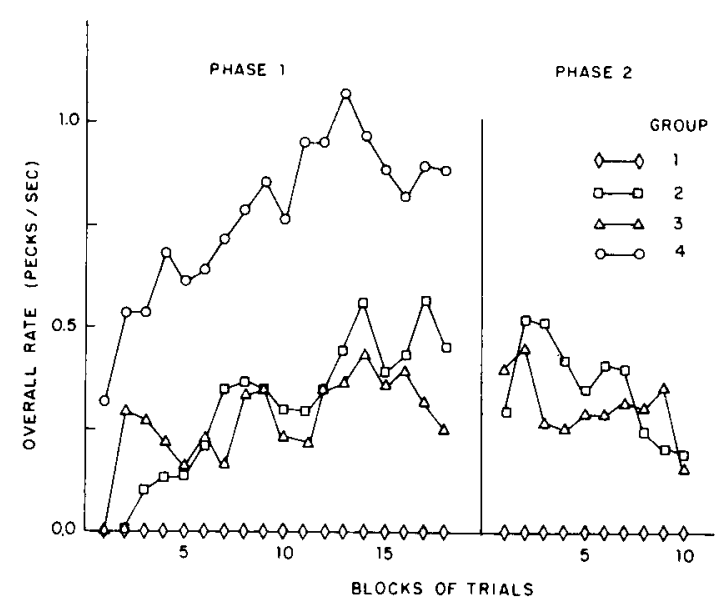

Figure 3. The mean overall rate of responding during trials is shown for the different experimental groups. In Phase 1, each point is based on the four-session ( 20 Irials) mean for each subject In Phase 2, all block means are based on 20 trials per subject. pecking movements than were recorded by the microswitch behind the response key. The mean overall observed response rates were $1.15,0.73$, and 1.56 responses/sec for Groups 2, 3, and 4, respectively.

The difference among groups in speed of acquisition was assessed by analyses of various criteria. The median number of trials to the first response for Groups 2, 3, and 4 were 28, 29, and 12.5 , respectively. For purposes of analysis, subjects that never responded in Group 1 were assigned scores of 360 and a Kruskal-Wallace analysis of variance by ranks showed that the groups differed reliably on this criterion $(\mathrm{H}=31.62, \mathrm{p}<.001)$. The groups also differed in the number of trials needed to satisfy a criterion of responses on three out of four consecutive trials $(H=14.39, \mathrm{p}<.001)$. The median number of trials to reach this criterion was $68,66.5$, and 39.5 for Groups 2, 3, and 4, respectively.

In an overall analysis of the data, the groups did not differ reliably in the latency to respond on trials with a response $[F(2,12)=1.02, p>.05]$. During the first five blocks, however, Group 2, with an average latency of $6.84 \mathrm{sec}$, Group 3, with an average latency of $4.23 \mathrm{sec}$, and Group 4, with an average latency of $4.28 \mathrm{sec}$, were significantly different from one another $[F(2,12)=4.68, p<.05]$. The groups did not reliably differ from one another, on the basis of latency, after the fifth block.

An analysis of the transformed (logged) running rates, that is, the rate of responding following the first response, showed a pattern similar to the one previously described for overall rate of responding. The highest running rate was shown by Group 4 subjects, and an intermediate and equal level of responding was observed in Groups 2 and 3. There was a significant effect of treatments $[F(3,15)=9.00$, $\mathrm{p}<.01]$, blocks $[\mathrm{F}(17,255)=6.85, \mathrm{p}<.01]$, and Treatments by Blocks interaction $[\mathrm{F}(51,255)=1.88$, $p<.01]$. The latter effect is again primarily the result of the failure of Group 1 subjects to peck the key.

In summary, the Phase 1 data showed that Group 4 subjects acquired responding sooner and maintained higher levels of responding than the other groups. Groups 2 and 3 did not differ from one another, and subjects in Group 1 did not exhibit any autoshaped keypecking at all.

The durations of feeder presentations were reversed for Groups 2 and 3 during the second phase of the experiment. The right side of Figure 2 shows that this manipulation did not produce a systematic change in the mean probability of pecking. A statistical comparison of each subject's mean probability during the last five blocks of Phase 1 with the first five blocks of Phase 2 failed to show a significant effect of the reversal $[t(8)=1.34, p>.05]$. During 
Phase 2, as in Phase 1, Groups 2 and 3 did not differ in response probability from one another $[F(1,7)=.10, p>.05]$.

The right side of Figure 3 shows that the reversal of feeder durations did not alter the overall rate of responding. A within-subject comparison of the effects of feeder durations during the last 5 days of Phase 1 and the first 5 days of Phase 2 did not detect any significant change $[\mathrm{t}(8)=.17, \mathrm{p}>.05]$. Furthermore, the two groups also did not differ on this measure throughout Phase $2[\mathrm{~F}(1,7)=.01$, $p>.05]$. Analyses of running rates and latencies within groups (Phase 1 vs. Phase 2) and between groups (Phase 2) also failed to show a systematic effect of varying feeder duration. Additionally, the observational data collected during the last five sessions of Phase 2 failed to show a systematic difference between groups. The mean overall observed response rates were .78 and .94 responses $/ \mathrm{sec}$ for Groups 2 and 3, respectively.

Subjects in Group 1 were switched from a $60-\mathrm{sec}$ feeder to a 4-sec feeder during the second phase of the experiment. The time from US offset to CS onset was maintained at $24 \mathrm{sec}$ throughout both phases. The reduction in feeder duration did not engender significant responding. The individual subjects in this group responded on $0,1,1$, and 2 of the 200 trials in this phase of the experiment.

\section{DISCUSSION}

Previous research has shown that the rate of acquisition and level of maintained responding is directly related to the duration of the ITI (Gibbon et al., 1977; Terrace et al., 1975) or to the duration of the interreinforcement interval (Groves, 1974). On the basis of temporal factors alone, Groups 1 and 2 and Groups 3 and 4 of the current experiment might be expected to be equivalent if reinforcer durations are included in the functional time between trials. The results of the current experiment argue against this interpretation. In both speed of acquisition and maintenance levels, the groups ordered themselves in direct relation to ITI duration, excluding reinforcer duration. Subjects in Group 1, with a 24-sec ITI, failed to keypeck; Group 2 and Group 3 subjects acquired and maintained moderate levels of responding with an 80-sec ITI; and Group 4 subjects, which were exposed to a 136-sec ITI, acquired keypecking more rapidly and maintained a higher level of responding than the other groups of the experiment. These results suggest that reinforcer durations do not operate as part of the intertrial interval. Alternatively, they do suggest that the time interval of importance in obtaining the trial spacing effect begins with the offset of the US and ends with the onset of either the next CS or US.
Groups 2 and 3, then, only differed in the feeder duration that followed each CS presentation. The duration of grain presentation for Group 3 subjects was 15 times that received by Group 2 subjects during Phase 1. These two groups, however, were not different from one another either in the analyses of the acquisition criteria or in any of the measures of maintained responding. The only difference between the two groups was in the average latency on trials with a response during the first 100 trials of the experiment. The subjects exposed to the longer feeder duration showed shorter latencies than the subjects exposed to the brief feeder.

When the feeder durations were reversed for Groups 2 and 3, none of the measures examined in this study showed a systematic change. Thus, as in previous research (Balsam et al., 1978; Perkins et al., 1975), neither the between-group comparisons of Phases 1 and 2 nor the within-group comparisons of Phase 1 to Phase 2 yielded any evidence of a systematic effect of feeder duration on maintained responding. It should be noted that although pigeons did make many off-key responses, the data obtained through direct observations also failed to show an effect of this manipulation. The failure to find a feeder duration effect is, therefore, not the result of measurement error (see Balsam et al., 1978; Perkins et al., 1975, Experiment 7).

One might hypothesize that the failure to find a feeder-duration effect in the current study was the result of diminishing whatever motivational advantage a long feeder provides by decreasing the drive level of subjects through satiation. This alternative seems very unlikely for several reasons. First, only two birds in Phase 1 and one bird in Phase 2 showed any consistent weight gain as a result of being exposed to the $60-\mathrm{sec}$ feeder duration. Weight changes therefore do not account for the failure to find a difference between the remaining birds of Groups 2 and 3 . Secondly, the birds that did gain weight did not show a decreasing tendency to respond with increased exposure to the 60 -sec feeder duration. Lastly, within-session satiation effects were not evident in this experiment. The Phase 1 data were analyzed in terms of the probability of a response as a function of ordinal trial position within a session. For all groups, the probability of responding did not decline as ordinal position increased, as would be predicted by a local satiation hypothesis. Thus, it does not seem reasonable to attribute the lack of a feeder-duration effect to changes in satiation levels.

The effects of varying US duration in other classical conditioning preparations are generally consistent with the findings of the current experiment. Studies employing between-group comparisons have failed to find evidence of greater conditioning with longer US durations in GSR conditioning (Coppock 
\& Chambers, 1959; Furedy, 1967; Salz, Kitai, \& Asdourian, 1963), eyeblink conditioning in humans (Meiselman \& Moore, 1965; Runquist \& Spence, 1959), and rabbits (Frey \& Butler, 1973), in the effectiveness of a CS as a punisher (Mowrer \& Solomon, 1954), and in heart-rate conditioning (Wegner \& Zeaman, 1958). In autoshaping, the between-group comparison made by Balsam et al. (1978) and the results of the current study failed to show an effect of varying feeder duration. In the Perkins et al. (1975, Experiment 7) study, subjects exposed to a 1 -sec feeder duration responded at a lower rate than subjects exposed to a longer feeder duration. Although feeders were operated for $5 \mathrm{sec}$ on trials during which birds did not eat in this condition, it is possible that subjects did not obtain all of the programmed reinforcers. The lower rate in the 1-sec group therefore may not be attributed to a direct effect of feeder duration, inasmuch as this manipulation might be confounded with changes in the probability of reinforcement and an omissionlike contingency.

The failure to find a between-subjects effect of US duration is surprising for two reasons. First, when two USs of equal intensity but different durations are associated with different CSs within the same session, subjects often show a sensitivity to the manipulation. Although heart-rate conditioning does not seem to follow this pattern (Church, LoLordo, Overmier, Solomon, \& Turner, 1966; Overmier, 1966), nictitating membrane CRs (Ashton, Bitgood, \& Moore, 1969), autoshaped keypecking (Balsam et al., 1978; Perkins et al., 1975), and conditioned emotional responses (Overmier, 1966) all show more vigorous CRs with longer US durations. In GSR conditioning, Bitterman, Reed, and Krauskopf (1952) found a greater CR to a stimulus associated with the longer shock duration, but the difference was not statistically significant. This suggests that the US duration effect depends on a comparison involving two distinct signals correlated with different US durations within the same session. This comparison may be between the two signals themselves, or the different signals may each be independently compared to continuously present background stimuli whose value is jointly determined by all reinforcer durations within each session (Gibbon \& Balsam, in press).

Secondly, US intensity, quality, and numerosity all exert a reliable effect on asymptotic response measures. In appetitive salivary conditioning, the quantity of food US has been shown to be directly related to the vigor of the CR (Gantt, 1938; Wagner et al., 1964). This finding holds as well for a variety of other preparations, including acid-induced salivary conditioning (Feather, Delse, \& Bryson, 1967; Warstler \& Ost, 1965), GSR conditioning (Boring \& Morrow, 1968), human eyeblink conditioning (Prokasy \&
Harsanyi, 1968; Spence, 1953; Spence, Haggard, \& Ross, 1958; Spence \& Platt, 1966), conditioned emotional response procedures (Annau \& Kamin, 1961; Ghiselli \& Fowler, 1976), finger withdrawal (Elias, 1965), heart-rate conditioning (Dykman \& Gantt, 1959; Sideroff, Schneiderman, \& Powell, 1971), and conditioning of the nictitating membrane in rabbits (Ashton et al., 1969; Smith, 1968).

It is surprising that US duration does not affect behavior similarly. This discrepancy suggests that the onset of the US is more important in determining the vigor of the CR than is either the total US duration or the average quantity of US per unit time. Along these lines, long intermittent USs have been shown to support higher levels of conditioned responding than continuous USs of equal duration (Furedy, 1967; Overmier, 1968).

\section{REFERENCES}

Annau, Z., \& Kamin, L. J. The conditioned emotional response as a function of intensity of the US. Journal of Comparative and Physiological Psychology, 1961, 54, 428-432.

Ashron, A. B., Bitgood, S. C., \& Moore, J. W. Auditory differential conditioning of the rabbit nictitating membrane response. III. Effects of US shock intensities and duration. Psychonomic Science, 1969, 15, 127-128.

Balsam, P. D., Brownstein, A. J., \& Shull, R. L. Effects of varying the duration of grain presentation on automaintenance. Journal of the Experimental Analysis of Behavior, 1978, 29, 27-36.

Bitterman, M. E., Reed, P., \& Krauskopf, J. The effect of the duration of the unconditioned stimulus upon conditioning and extinction. American Journal of Psychology, 1952, 65, 256-262.

Boring, F. W., \& Mornow, M. C. Effects of UCS intensity upon conditioning and extinction of the GSR. Journal of Experimental Psychology, 1968, 77, 567-571.

Church, R. M., Lolordo, V., Overmier, J. B., Solomon, R. L., \& TURNEn, L. H. Cardiac responses to shock in curarized dogs: Effects of shock intensity and duration, warning signal, and prior experience with shock. Journal of Comparative and Physiological Psychology, 1966, 62, 1-7.

Coppock, H. W., \& Chambers, R. M. GSR conditioning: An illustration of useless distinctions between "types" of conditioning. Psychological Reports, 1959, 5, 171-177.

Dykman, R. A., \& GantT, W. H. The parasympathetic component of unlearned and acquired cardiac responses. Journal of Comparative and Physiological Psychology, 1959, 52, 163-167.

Elias, M. F. The relation of drive to finger-withdrawal conditioning. Journal of Experimental Psychology, 1965, 70, 109-116.

Feather, B. W., Delse, F. C., \& Bryson, M. R. Human salivary conditioning: Effects of unconditioned-stimulus intensity. Journal of Experimental Psychology, 1967, 74, 389-392.

Frey, P., \& Butler, C. Rabbit eyelid conditioning as a function of unconditioned stimulus duration. Journal of Comparative and Physiological Psychology, 1973, 85, 289-294.

Furedy, J. J. Classical appetitive conditioning of the GSR with cool air as the UCS, and the roles of the UCS onset and offset as reinforcers of the CR. Journal of Experimental Psychology, $1967,75,73-80$.

Gan'T, W. H. The nervous system secretion of saliva: The rela tion of the conditioned reflex to the intensity of the unconditioned stimulus. American Journal of Physiology, 1938, 123, $74-75$ 
GHiselli, W., \& Fowler, H. Signaling and affective functions of conditioned aversive stimuli in an appetitive choice discrimination: US intensity effects. Learning and Motivation, 1976, 7, 1-16.

Gibbon, J., Baldock, M., Locurto, C., Gold, L., \& Terrace, H. S. Trial and intertrial durations in autoshaping. Journal of Experimental Psychology: Animal Behavior Processes, 1977, 3, 264-284.

Gibbon, J., \& Balsam, P. D. Spreading association in time. In C. Locurto, H.S. Terrace, \& J. Gibbon (Eds.), Autoshaping and conditioning theory. New York: Academic Press, in press.

Groves, L. C. The effects of trial and cycle duration on automaintenance in the pigeon. Unpublished doctoral dissertation, University of North Carolina at Greensboro, 1974.

Jenkins, H. M., \& Moore, B. R. The form of the autoshaped response with food or water reinforcers. Journal of the Experimental Analysis of Behavior, 1973, 20, 163-181.

Meiselman, H. L., \& Moone, J. W. The effects of percentage reinforcement, UCS duration, and experience with procedure on the conditioned eye-lid response. Psychonomic Science, 1965, 3, 335-336.

Mowrer, O. H., \& Solomon, L. N. Continguity vs, drivereduction in conditioned fear: The proximity and abruptness of drive-reduction. American Journal of Psychology, 1954, 67, $15-25$.

Overmier, J. B. Instrumental and cardiac indices of Pavlovian fear conditioning as a function of US duration. Journal of Comparative and Physiological Psychology, 1966, 62, 15-20.

Overmier, J. B. Differential Pavlovian fear conditioning as a function of the qualitative nature of the UCS: Constant versus pulsating shock. Conditional Reflex, 1968, 3, 175-180.

Perkins, C. C., Beavers, W. O., Hancock, R. A., Hemmendinger, P. C., Hemmendinger, D., \& Ricci, J. A. Some variables affecting rate of key pecking during responseindependent procedures (autoshaping). Journal of the Experimental Analysis of Behavior, 1975, 24, 59-72.

Prokasy, W. F., \& Harsanyi, M. A. Two-phase model for human classical conditioning. Journal of Experimental Psychology, 1968, 78, 359-368.

Runquist, W. N., \& Spence, K. W. Performance in eyelid conditioning as a function of UCS duration. Journal of Experimental Psychology, 1959, 57, 249-252.
Salz, E., Kitai, S., \& Asdourian, D. Two-factor theory: Preliminary study of relationship between drive reduction and UCS duration. Psychological Reports, 1963, 12, 757-758.

Sideroff, S., Schneiderman, N., \& Powell, D. A. Motivational properties of septal stimulation as the US in classical conditioning of heart rate in rabbits. Journal of Comparative and Physiological Psychology, 1971, 74, 1-10.

Sмгтн, M. C. CS-US interval and US intensity in classical conditioning of the rabbit's nictitating membrane response. Journal of Comparative and Physiological Psychology, 1968, 66, 679-687.

SPENCE, K. W. Learning and performance in eyelid conditioning as a function of intensity of the UCS. Journal of Experimental Psychology, 1953, 45, 57-63.

Spence, K. W., Haggard, D. F., \& Ross, L. E. UCS intensity and the associative (habit) strength of the eyelid CR. Journal of Experimental Psychology, 1958, 55, 404-411.

SPence, K. W., \& PlatT, J. R. UCS intensity and performance in eyelid conditioning. Psychological Bulletin, 1966, 65, 1-10.

Terrace, H. S., Gibbon, J., Farrell, L., \& Baldock, M. D. Temporal factors influencing the acquisition and maintenance of an autoshaped keypeck. Animal Learning \& Behavior, 1975, 3, 53-62.

Wagner, A. R., Siegel, S., Thomas, E., \& Ellison, G. Reinforcement history and the extinction of a conditioned salivary response. Journal of Comparative and Physiological Psychology, 1964, 58, 354-358.

Wasserman, E. A. Pavlovian conditioning with heat reinforcement produces stimulus-directed pecking in chicks. Science, $1973,181,875-877$.

Warstler, H. E., \& Ost, J. W. P. Classical salivary conditioning in the dog: Effects of 3 US intensities. Journal of Comparative and Physiological Psychology, 1965, 60, 256-259.

WEGNeR, N., \& ZEAMAN, D. Strength of cardiac conditioned responses with varying unconditioned stimulus durations. Psychological Review, 1958, 65, 238-241.

Woodruff, G., \& Williams, D. R. The associative relation underlying autoshaping in the pigeon. Journal of the Experimental Analysis of Behavior, 1976, 26, 1-13.

(Received for publication December 13, 1978; revision accepted April 4, 1979.) 